\title{
Disjunctive Answer Options Complicate Communication - A Linguistic Analysis of the Danish EQ-5D (5L) Version
}

Esben Nedenskov Petersen

University of Southern Denmark

Birgitte Nørgaard ( $\nabla$ binorgaard@health.sdu.dk)

University of Southern Denmark

\section{Research Article}

Keywords: Gricean pragmatics, epistemology, context sensitivity, EQ-5D, EuroQol

Posted Date: December 16th, 2021

DOI: https://doi.org/10.21203/rs.3.rs-1170908/v1

License: (c) (1) This work is licensed under a Creative Commons Attribution 4.0 International License.

Read Full License 


\section{Abstract}

Background: EQ-5D is an internationally acknowledged tool for assessing health-related quality of life. Our aim was to examine how pragmatic dynamics may influence answers to the EQ-5D-5L and how the logical structure of answer options affects the communication of the questionnaire.

Methods: We performed a 3-step linguistic analysis building on the seminal work of Grice, including 1) examination of the lexical meanings of the answer options, 2) considerations of how conversational maxims might affect the respondent's interpretation of answer options when two or more answer options in an item are compatible, and 3) analysis of how the questionnaire's context might counteract the problem of omissions of answer options by shifting the meaning of context-sensitive expressions.

Results: All items exhibit compatibilities and omissions. In items 1 and 3, ordinary conversational norms provide sufficient guidance to determine how a respondent should decide between compatible answer options. In items 2, 4, and 5, the available answer options complicated the communicative task for some respondents.

Conclusions: In items where answer options have a disjunctive structure, respondents relying on Gricean maxims of conversation will have to depend on their individual understanding of fine-grained details concerning the questionnaire's purpose and may have to weigh how conflicting norms should be balanced.

\section{Introduction}

Health-related quality of life has increasingly become a core outcome in health delivery as guidance for treatment, care, and rehabilitation. EQ-5D is an internationally acknowledged generic tool for assessing health-related quality of life and, thus, measures, compares, and values health status across disease areas (1). The EQ-5D was developed in 1990, covering five dimensions: mobility, self-care, usual activities, pain/discomfort, and anxiety/depression. It is based on the assumption that health status can be modeled on a unidimensional continuum and represented by a single index score (2). Furthermore, the instrument allows for calculating quality-adjusted life-years (Qalys) reflecting the quality and quantity of life to be combined into a single index (3). The index score is based on population norms used as reference values (4), and Qalys are, among other things, valuable for recommendations of drug effects (5). Initially, each dimension had three levels (e.g., No pain or discomfort, Moderate pain or discomfort, or Extreme pain or discomfort). However, due to ceiling effect challenges, a five-level version was introduced in 2009 (1) with an expected increased discriminative capacity and sensitivity to change compared to the EQ-5D-3L as well as smaller ceiling effects (6). The Danish version of EQ-5D-3L was developed and ratified in 1996 (4), and the five-level version (5L) in 2009 demonstrated valid redistribution, reduced ceiling, and improved discriminatory power (7).

Although internationally acknowledged and widely implemented, and despite continuous attention to sensitivity and discriminative capacity, the acceptance of a single index score as a reflection of the 
quality and quantity of life of every human being, ranging from completely healthy to severely ill, is striking. To decide on their answers to questionnaire items, co-operative respondents presumably opt for the answer options that they think best represent the facts about the questions they are asked. When answer options are given in ordinary language terms, such choices, to a large extent, depend on the lexical meanings of these language fragments together with the meaning of their corresponding questions. Lexical meaning, however, is not the only factor affecting how answer options are interpreted. As linguistic pragmatics explain, a speaker's use and interpretation of language are heavily influenced by conversational norms and the assumption that others rely on his/her conformity with such norms to interpret his/her conversational contributions (8-10).

Our aim was to examine how pragmatic dynamics may influence answers to the items in the EQ-5D-5L where the available answer options have a disjunctive form. Rather than focusing on a single parameter that might affect responses, we considered the possible effects of both scalar implicatures $(11,12)$ and less predictable pragmatic inferences.

\section{Methods}

We performed a linguistic analysis building on the seminal work of Grice (8).

According to Grice, speakers generally conform to an overarching co-operative principle (CP) enjoining interlocutors to "Make your contribution such as is required, at the stage at which it occurs, by the accepted purpose or direction of the talk exchange in which you are engaged" (8). On this approach, complying with $\mathrm{CP}$ requires every speaker to conform to several more specific conversational maxims:

QUALITY: Try to make your contribution one that is true

1. Do not say what you believe to be false

2. Do not say that for which you lack evidence

QUANTITY:

1. Make your contribution as informative as is required (for the current purposes of the exchange)

2. Do not make your contribution more informative than is required

RELATION: Be relevant

MANNER: Be perspicuous

1. Avoid obscurity of expression

2. Avoid ambiguity

3. Be brief (avoid unnecessary prolixity)

4. Be orderly 
Traditional Griceans and more recent Neo-Gricean approaches (9) argue that these norms, or closely adjacent norms, are crucial $(13,14)$ to how we structure and interpret linguistic communication. For example, if someone says that he/she is desperate for a meal and asks for the way to the nearest diner, and you know that the nearest diner closed for the night, conformity with $\mathrm{CP}$ will prohibit you from giving $\mathrm{him} /$ her the directions to the nearby diner without informing them that it is closed for the night. If you did, in fact, give your interlocutor the directions without any supplementary remarks, the presumption that you are observing $\mathrm{CP}$ would lead them to the mistaken conclusion that you have no more relevant information to convey (15). What you might say instead is that the nearest diner is closed since this would be a more appropriate answer given the purpose of the conversation. Your understanding of what your interlocutor needs to know affects how you answer his/her question.

Pragmatic dynamics also influence answers to questionnaires $(16,17)$. Respondents have been shown to rely on conversational norms for disambiguation of ambiguous questions (18) as well as other aspects of questionnaire interpretation (19).

Pragmatic dynamics, however, are not the only source of contextual effects on linguistic communication. The significance of context also comes from semantic context-sensitivity. Whereas some linguistic expressions retain the same meaning across different contexts, many do not. Ordinary language is full of context-sensitive expressions that have their meaning on a particular occasion determined by features of their context of utterance. On the standard account of gradable adjectives, for example, such terms are context sensitive (20). The standard analysis of these terms implies that the meaning of a gradable adjective, such as "little", changes because shifting the context of utterance may alter the threshold degree of smallness for qualifying as little. That an administered amount of morphine is "little" means one thing when the patient is a large man with extensive third-degree burns but plausibly means something else when the patient is a small child. Hence, semantic context-sensitivity potentially affects the interpretation of answer options in any questionnaire using gradable adjectives.

\section{Analysis}

To examine the interconnected dynamics of lexical meaning and pragmatics and the significance of semantic context sensitivity in the Danish EQ-5D, we employed a three-step analysis.

The first step of the analysis examined the lexical meanings of the answer options belonging to a questionnaire item to describe how they relate semantically to each other and to the properties that the items are intended to measure. This part of the analysis served to identify what we refer to as compatibilities and omissions. A compatibility occurs when a questionnaire item only allows a single answer, although two or more answer options under the item may be true simultaneously. Consider, for example, the question "How tall are you?" with the possible answer options "More than $0 \mathrm{~cm}$ and less than or equal to $100 \mathrm{~cm}$ ", "More than $100 \mathrm{~cm}$ and less than or equal to $200 \mathrm{~cm}$ ", "More than a $150 \mathrm{~cm}$ and less than or equal to $200 \mathrm{~cm}$ ", "More than $200 \mathrm{~cm}$ ". Because the second and third answer options may both be true simultaneously, this is an example of compatibility. The example also illustrates that there is 
always compatibility when the truth of one answer option entails the truth of another. An omission occurs when the lexical meanings of answer options under a questionnaire item are such that there could be situations where no answer option is true on a literal interpretation. Consider, for example, the question "How tall are you?" with the possible answer options "More than $0 \mathrm{~cm}$ and less than or equal to $100 \mathrm{~cm}$ ", "More than a $150 \mathrm{~cm}$ and less than or equal to $200 \mathrm{~cm}$ ", and "More than $200 \mathrm{~cm}$ ". In this simple example, there is an omission because none of the available answer options would be true of a person with a height between 100 and $150 \mathrm{~cm}$. Both compatibilities and omissions may have the consequence that respondents cannot rely solely on lexical meaning when instructed to find the best or most suitable answer under a questionnaire item. Accordingly, respondents confronting compatibilities or omissions are likely to sometimes draw on pragmatic norms to identify the most appropriate answer option available.

In the second step of our analysis, we considered how conversational maxims might affect the respondent's interpretation of answer options incorporating a compatibility.

In the third step, we examined the same question with respect to omissions analysis and also considered how the context of the questionnaire might counteract the problem with omissions by shifting the meaning of context-sensitive expressions.

\section{Results}

There are three items in the EQ-5D with disjunctive answer options: Item 2, 4, and 5. We focus on item 4 to report the results of our analysis. Rather than the wording from the English version of the questionnaire, we provide our translation of the Danish version to best capture the features of the Danish EQ-5D. The translations are presented in brackets surrounded by double quotation marks.

\section{Lexical meanings}

The Danish EQ-5D begins with the general instruction “Under hver overskrift bedes du sætte kryds i DEN kasse, der bedst beskriver dit helbred IDAG" (“Under every headline, you are requested to check THE box that best describes your health TODAY"). In item 4, the headline is "SMERTER /UBEHAG" ("PAIN/DISCOMFORT"). The answer options are "Jeg har ingen smerter eller ubehag" ("I have no pain or discomfort"), "Jeg har lidt smerter eller ubehag" ("I have little pain or discomfort"), "Jeg har moderate smerter eller ubehag" ( I have moderate pain or discomfort"), "Jeg har stærke smerter eller ubehag ( "I have strong pain or discomfort"), and "Jeg har ekstreme smerter eller ubehag" ( I have extreme pain or discomfort"). We examine how conversational norms should be expected to affect the interpretation of these answer options.

If levels of pain and discomfort were always perfectly aligned, the analysis of compatibilities and omissions in item 4 would be relatively simple. On this assumption, a lexical analysis can ignore the disjunctive form of the answer options, and treat them exclusively as questions about pain, because a respondent's true answer about the disjunct concerning pain would correspond to her true answer about 
the disjunction. Given the assumption that pain, and discomfort are aligned, our analysis concludes that the first answer option is incompatible with all the rest. In the second option, "Lidt smerter" ("Little pain") has a semantic link to a scale ordering pains by their littleness, with the degree of littleness closest to zero as the maximum value. This semantic relation gives "Jeg har lidt smerter" the same meaning as "I have pain (at least as small as) little pains". "Moderat" (English "Moderate") has a similar link to a scale, which gives "Jeg har moderate smerter" the same meaning as "I have pains (at least as small as) moderate pains". Hence, because the threshold degree of littleness for qualifying as moderate is lower than the threshold degree of littleness for qualifying as little, a true answer to the second option entails a true answer to the third. The lexical meaning of "Stærke smerter" ("Strong pains") relates the fourth answer option to a scale ranking pains by order of their degree with the most extreme pain possible as the maximal value. The expression "Stærke smerter" means the same as "(pains as least as strong as) strong pains". Accordingly, since the fifth answer option "Jeg har ekstreme smerter" has the meaning of "I have (pain at least as great as) extreme pain" and "Jeg har stærke smerter" means the same as "I have (pain at least as great as) strong pain", the fifth answer option entails the fourth because extreme pain is at least as strong as strong pain.

In addition, because a respondent's level of pain and discomfort could simultaneously be stronger than moderate but less than strong, the item also has an omission, on the assumption that a respondent's pain and discomfort are at identical levels.

Things are considerably more complicated regarding situations where a respondent's levels of pain and discomfort come apart. Whereas any degree of pain may be assumed to entail the same degree of discomfort, there is no entailment in the opposite direction. Nausea or dizziness, for example, may involve extreme discomfort with little or no related pain. Thus, every answer option that reports a non-zero level of discomfort is compatible with every answer option that reports a lower degree of pain. The truth of "Jeg har ekstreme smerter eller ubehag" is compatible with all other answer options under the second item because the truth of its second disjunct "Jeg har ekstremt ubehag" ("I have extreme discomfort") is compatible with the truth of the first disjunct in all answer options. Put differently, the truth of the fifth answer option permits the truth of all the remaining disjunctive answer options because one might suffer extreme discomfort together with strong pains that are not extreme, moderate pains, little pain, and absence of pain, and a disjunction is true whenever one of its disjuncts is true (21). Analogously, the truth of the fourth answer option permits the truth of the third, second, and first answer options because a respondent may experience strong discomfort in combination with any of the following: moderate pain, little pain, or absence of pain. For similar reasons, the truth of the item's third answer option permits the truth of the second and first options, and the truth of the second option permits the truth of the first. None of these compatibilities are due to entailments because facts about pain levels do not follow from facts about discomfort.

\section{Conversational norms and pragmatic effects}


With respect to the effects of pragmatic norms on answer choices in item 2, the respondent's judgments about his/her levels of pain and discomfort are crucial. The key difference is between cases where the respondent judges that his/her level of pain is the same as his/her level of discomfort (relative to the categories of the questionnaire) and where he/she does not. Table 1 shows which answer options may be true when the levels of discomfort and pain are identical.

Table 1

True answer options in item 2 when the level of discomfort equals the level of pain

\begin{tabular}{|llllllll|}
\hline Combination & $\begin{array}{l}\text { Level of } \\
\text { discomfort }\end{array}$ & $\begin{array}{c}\text { Level of } \\
\text { pain }\end{array}$ & $\begin{array}{l}\text { Answer } \\
\text { option 5 }\end{array}$ & $\begin{array}{l}\text { Answer } \\
\text { option 4 }\end{array}$ & $\begin{array}{l}\text { Answer } \\
\text { option 3 }\end{array}$ & $\begin{array}{c}\text { Answer } \\
\text { option 2 }\end{array}$ & $\begin{array}{c}\text { Answer } \\
\text { option 1 }\end{array}$ \\
\hline 1 & Extreme & Extreme & True & True & & \\
\hline 2 & Strong & Strong & & True & & & \\
\hline 3 & Moderate & Moderate & & True & & \\
\hline 4 & Little & Little & & & True & True & \\
\hline 5 & 0 & 0 & & & & True \\
\hline
\end{tabular}

In the situations represented in Table 1, pragmatic dynamics are likely to affect how a respondent decides between compatible answer options. In these cases, the second option "Lidt smerte eller ubehag" ("Little pain or discomfort") is compatible with the third option "Moderat smerte eller ubehag" ("Moderate pain or discomfort") but also entails that the third option is true. Accordingly, because confirmation of the third option does not entail that the second option is true, the second option is more informative than the third. Hence, if both the third and second options are true of a respondent, the first maxim of quantity enjoins the respondent to opt for the second option to comply with the co-operative principle. Consequently, if the third answer option is true, pragmatic norms imply that selecting this option is only pragmatically permissible for a respondent when they are not in a position to affirm the second option. Assuming that ordinary pragmatic norms remain in place, scalar implicatures related to informativity (7-9), therefore, determine what the respective answer choices communicate.

Things are different regarding respondents who judge that their level of discomfort exceeds their level of pain. Table 2 provides a schematic overview of the answer options that may be true simultaneously for such respondents.

Table 2

True answer options in item 2 when the level of discomfort exceeds the level of pain 


\begin{tabular}{|llllllll|}
\hline Combination & $\begin{array}{l}\text { Level of } \\
\text { discomfort }\end{array}$ & $\begin{array}{l}\text { Level of } \\
\text { pain }\end{array}$ & $\begin{array}{l}\text { Answer } \\
\text { option } \mathbf{5}\end{array}$ & $\begin{array}{l}\text { Answer } \\
\text { option } \\
\mathbf{4}\end{array}$ & $\begin{array}{l}\text { Answer } \\
\text { option 3 }\end{array}$ & $\begin{array}{l}\text { Answer } \\
\text { option 2 }\end{array}$ & $\begin{array}{c}\text { Answer } \\
\text { option 1 }\end{array}$ \\
\hline 1 & Extreme & Strong & True & True & & & \\
\hline 2 & Extreme & Moderate & True & True & True & & \\
\hline 3 & Extreme & Little & True & True & True & True & \\
\hline 4 & Extreme & 0 & True & True & & & True \\
\hline 5 & Strong & Moderate & & True & True & & \\
\hline 6 & Strong & Little & & True & True & True & \\
\hline 7 & Strong & 0 & & True & & & True \\
\hline 8 & Moderate & Little & & & True & True & \\
\hline 9 & Moderate & 0 & & & True & & True \\
\hline 10 & Little & 0 & & & True & True & True \\
\hline
\end{tabular}

In several of these situations, there are true answer options that are not entailed by another true option. These situations are represented by combination $2,3,4,5,6,7,9$, and 10 . The absence of an entailment relation implies that the Quantity maxim does not suffice to resolve which answer a respondent should opt for. Consider, for example, the situation represented by row 3 where a respondent judges his/her discomfort to be extreme but considers his/her pain to be little. In such a case, option 5 is more informative than option 4 because the former entails the latter, and option 2 is more informative than option 3 because the truth of option 2 entails the truth of option 3. But there is no entailment from option 5 to option 2 or vice versa. Hence, the respondent is confronted with a problem that neither Quality nor Quantity resolves.

The only Gricean maxim that may be helpful in this predicament is Relevance. A respondent's decision about the appropriate answer may be aided by his/her assessment as to which information is most relevant to the addressee. Which option Relevance recommends, however, depends on the respondent's construal of the questionnaire item's communicative purpose. Although we can speculate about a respondent's likely assessment of the item's primary communicative purpose, it hence remains an open question what a respondent with extreme discomfort and little pain would answer to item 2 when guided by pragmatic norms. The same kind of problem arises for respondents in the situations represented by rows $2,3,4,5,6,7,9$, and 10 in Table 2.

Depending on how the respondent construes the purpose of the questionnaire, the Relevance maxim may conflict with the Quantity maxim. Consider a respondent who assumes that the questionnaire is primarily intended to capture the maximum extent to which a person is affected by either discomfort or pain. Given this understanding of the purpose of the questionnaire, Relevance should lead him/her to choose option 
5 in the situation represented by row 3 . But if the same assumption is upheld with respect to a respondent regarding the situations represented by row 8 , there is a conflict between the recommendations of the Relevance and Quantity maxims. Relevance would suggest that the respondent should choose option 3 to avoid signaling that both pain and discomfort are minor. In contrast, because the truth of option 2 entails the truth of option 3, Quantity would suggest that the respondent should choose option 2 to avoid indicating that he/she is not in a position to affirm option 2. Accordingly, answering item 2 of the EQ-5D may require a respondent to resolve a tension between conflicting recommendations from different pragmatic norms. With other conceptions of the questionnaire's purpose, conflicts between Relevance and other maxims may arise in situations represented by other rows in Table 2.

There are also situations in which a respondent's level of discomfort is greater than the level of pain while either discomfort or pain is at a level below strong but above moderate. These situations are represented in Table 3.

Table 3

True answers in item 2 when the level of discomfort exceeds the level of pain, and discomfort or pain is at a level below strong but above moderate

\begin{tabular}{|c|c|c|c|c|c|c|c|}
\hline Combination & $\begin{array}{l}\text { Level of } \\
\text { discomfort }\end{array}$ & $\begin{array}{l}\text { Level of } \\
\text { pain }\end{array}$ & $\begin{array}{l}\text { Answer } \\
\text { option } \\
5\end{array}$ & $\begin{array}{l}\text { Answer } \\
\text { option } \\
4\end{array}$ & $\begin{array}{l}\text { Answer } \\
\text { option } \\
3\end{array}$ & $\begin{array}{l}\text { Answer } \\
\text { option } \\
2\end{array}$ & $\begin{array}{l}\text { Answer } \\
\text { option } \\
1\end{array}$ \\
\hline 1 & Extreme & $\begin{array}{l}\text { Between } \\
\text { strong and } \\
\text { moderate }\end{array}$ & True & True & & & \\
\hline 2 & Strong & $\begin{array}{l}\text { Between } \\
\text { strong and } \\
\text { moderate }\end{array}$ & & True & & & \\
\hline 3 & $\begin{array}{l}\text { Between } \\
\text { strong and } \\
\text { moderate }\end{array}$ & Moderate & & & True & & \\
\hline 4 & $\begin{array}{l}\text { Between } \\
\text { strong and } \\
\text { moderate }\end{array}$ & Little & & & True & True & \\
\hline 5 & $\begin{array}{l}\text { Between } \\
\text { strong and } \\
\text { moderate }\end{array}$ & 0 & & & & & True \\
\hline
\end{tabular}

Some of these situations may also involve conflicts between Relevance and other maxims. In the situation represented by row 4, both answer options 2 and 3 will be true, whereas option 2 will be more informative than option 3. Option 3 , however, would be closer to a true representation of the respondent's level of discomfort. If the respondent does not experience any pain, this tension will be even higher 
because there will be an even more significant difference between the only true answer, option 1, and the answer option that best represents the respondent's level of discomfort, either options 3 or 4 . Furthermore, if a respondent in either of these situations assumes that it is important for the addressee that reported answers do not underestimate the degree of either discomfort or pain that is highest for the respondent, Relevance might encourage him/her to answer "Stærk smerte eller ubehag" ("Strong pain or discomfort"), although this option is false, and whether available answer options are true. In the situation represented by row 1 in Table 3, the potential conflict confronting the respondent is between selecting option 5 to ensure truthfulness or abandoning truthfulness to somehow take into account that the level of pain is noticeably lower than the degree of discomfort.

It is possible, however, that the complexity of choosing an answer in the situations represented by Table 3 will be mitigated somewhat by contextual adjustment of the meanings of "Moderat" and "Stærk" ("Moderate" and "Strong"). If such modulation adjusts the extension of either "Stærk smerte eller ubehag " or "Moderat smerte eller ubehag" to eliminate the gap between the two categories, the subsequent interpretative circumstances will be akin to those represented by row 2 or 3 in Table 1, or row 1, 2, 5, 6, 7, 8, or 9 in Table 2. But although this dynamic might reduce interpretative complexity, the issues related to compatibilities would leave considerable obstacles for some respondents to navigate.

\section{Omissions and context-sensitivity}

In addition to the many compatibilities, there is also an omission in the fourth item. It is possible for a respondent to simultaneously have pain that is worse than moderate pain but less severe than strong pain while experiencing discomfort, which is worse than moderate discomfort but less severe than strong discomfort. Hence, there may be cases where none of the item's five answer options is true about the respondent.

None of the Gricean maxims determine how a respondent in such a predicament should respond. Considering the central significance of truthfulness in communication $(22,23)$, a likely course of action would be for the respondent to decide his/her answer by choosing the option that he/she considers closest to the truth. In that case, he/she would be observing the first maxim of Quality to the highest extent possible, given their circumstances. The other maxim most likely to affect a respondent's decision is relevance because of how close the relevance maxim is to the overarching co-operative principal (CP). How this maxim might affect a respondent's choice of answer cannot be determined based on basic pragmatic principles because its influence on a respondent depends on how the respondent construes the purpose of the information exchange mediated by the questionnaire.

It is also possible that the semantic context sensitivity of "Stærk" and "Moderat" ("Strong") and ("Moderate") is more significant than pragmatic norms to how the omission in item 4 affects a respondent's answer. Because the meaning of a context-sensitive term is determined by its context of use, the questionnaire may shift the meanings of "Stærk" and "Moderat" to close the logical gap between answer options 4 and 3. Thus, although the linguistically encoded meanings of the questionnaire's terms 
do not generally exclude the possibility of a level of impairment between the categories "Stærk" and "Moderat", the contextually determined meanings of the terms in the EQ-5D might preclude this possibility. This situation might occur either by lowering the level of impairment that qualifies as "Stærk" or raising the level of impairment that would still be regarded as low enough to qualify as "Moderat".

\section{Scope of analysis}

Whether this analysis of item 4 can be extended to the other items with disjunctive questions (i.e., items 2 and 5) depends on the relations between the disjuncts in their answer options. Item 2 asks about the degree to which the respondent can wash themselves or get themselves dressed, "Vaske mig" ("Wash myself") or "Klæde mig selv på" ("Get myself dressed"), whereas item 5 enquires about the degree to which the respondent experiences " $Æ$ Engstelighed" ("Anxiety") or "Depression" ("Depression"). If a respondent's difficulty with getting washed and getting dressed are always on the same level, and depression and anxiety are always parallel to each other in severity, then the situations a respondent might be in when answering either item correspond to those in Table 1. If, on the other hand, the degree of depression is compatible with any degree of anxiety as long as the level of anxiety does not exceed the degree of depression, or vice versa, then the possible communicative circumstances of a respondent will be analogous to those in Tables 1, 2, and 3. Finally, if a person's degree of depression and anxiety do not restrict each other at all, the analog of Table 1, as well as two analogs of Table 2 and two analogs of Table 3 will be required to represent the situations that a respondent might be in when deciding how to answer item 5 of the EQ-5D.

\section{Discussion}

A questionnaire is a widely used, simple, and cheap instrument for research concerning both specific and generic populations' behaviors, attitudes, and beliefs, and it is crucial that the specific questionnaire is constructed to produce valid and trustworthy results. The validity of questionnaires in terms of the comprehension of its questions, and the repeatability of the responses, might still be challenged (22). Rigorous (statistical) validation of questionnaires has been recommended for decades, and the inclusion of content validity and cross-cultural adaptation has been internationally recommended and acknowledged at least since the description of the COSMIN guidelines in 2010 (23). Such validation includes cognitive interviews to investigate how responders interpret questions and how they choose an answer. This process of understanding the question and choosing the answer is described in four elements: the responder has to comprehend the question, retrieve the necessary information to answer, decide which information is required to answer, and, finally, choose the adequate answer (24). The cognitive interviews are considered the means to reveal these processes and, thus, contribute to the meaningfulness of a questionnaire as judged by the responders. There is, however, a risk that this process ignores the fact that responders (unconsciously) tend to answer in a socially desirable manner (fake good) $(25,26)$, and sometimes seek to give answers conforming to what they think is expected from them (27). 
A substantial linguistic analysis can serve to identify further pitfalls in questionnaires that might otherwise remain unrecognized despite a thorough and rigorous validation process.

Thus, despite claims of thorough semantic and linguistic testing during development and cultural adaptation $(28,29)$, we found several places where the communication of the EQ-5D is complicated by compatibilities or omissions. Because of the disjunctive form of their answer options respondents relying on conversational norms to decide between compatible answer options in item 2, 4, and 5 may be required to find a balance between conflicting maxims based on their personal understanding of a specific item's purpose. How a respondent striving for relevance and truthfulness answers the EQ-5D might, therefore, be influenced by well-attested pragmatic aspects of linguistic communication $(28,29)$ that are not directly related to the presence of the properties that the questionnaire is intended to measure.

Whereas the lexical and pragmatic analysis of the questionnaire extends general theoretical insights to the specific case without relying on verbal reports directly related to the EQ-5D questionnaire, the basis for the analysis is empirical, nonetheless. Its basic theoretical tenets are supported by empirical work in experimental pragmatics $(30,31)$, and other aspects of its significance to survey methodology are already well documented (17-19) . Our analysis does not offer a solution to the potential problems arising from the wording of questionnaire items. The aim is rather to add to conventional validation procedures and draw attention towards the fact that even data from rigorously validated questionnaires should be interpreted cautiously because they have multiple sources and may not reflect the facts that they are supposed to reflect.

\section{Limitations}

We acknowledge that our analysis is disrupted from actual practice and that theoretical analyses only have an indirect relation to practice. On the other hand, theoretical analyses are necessary to gain insight into unconscious reflections, and we find that our analysis offers useful insights into mental constructions and negotiations that cannot be revealed even using cognitive interviewing. They also avoid the concern that the procedure and setting of a cognitive interview might influence how a respondent reasons about a questionnaire and answers its questions (32). The analysis is restricted to the Danish questionnaire, which could be a limitation of the study considering the small linguistic area. There is, however, no reason to believe that such an analysis would have significantly different results if applied to other languages. Our purpose was not to suggest substantial revisions of an internationally acknowledged and widely used tool but to contribute to the understanding of the mental constructions and unconscious negotiations behind questionnaire answers-and, ideally, to encourage new instrument developers to include linguistic analyses in their validation processes. With respect to such processes, the kind of theoretical analysis that we have employed here has the advantage of potentially aiding the prequalification of questionnaires prior to more labor-extensive and costly empirical pre-testing of surface validity. 


\section{Conclusion}

Our analysis showed that the questionnaire has several compatibilities and at least one omission. Hence, respondents cannot rely solely on lexical meaning to choose between answer options leading to a problem concerning items with disjunctive answer options. In these items, respondents who try to choose their answer by relying on Gricean maxims of conversation will have to depend on their personal understanding of fine-grained details concerning the questionnaire's purpose and may have to weigh how conflicting norms should be balanced. This issue complicates the questionnaire's communication considerably and renders its precise interpretation unpredictable.

The purpose of this paper, however, is not to argue that the EQ-5D in its present form cannot be used for its intended purpose. Rather, our primary purpose is to demonstrate that certain linguistic factors that tend to be underappreciated in survey research may have a significant influence on how respondents answer the questionnaire. Our hope is also to call attention to the methodological potential of a type of linguistic analysis that may be highly valuable to survey methodology in health- and quality-of-life research, particularly in the prequalification phase prior to empirical pilot testing. Ideally, our analysis would help questionnaire developers and other researchers in the field see how their work might benefit from drawing on linguistic theorizing about semantic context sensitivity and pragmatic dynamics.

\section{Declarations}

\section{Ethics approval and consent to participate}

Not applicable

\section{Consent for publication}

Not applicable

\section{Availability and data materials}

Not applicable

\section{Competing interests}

Both authors declare that they have no conflicts of interests and no competing interests.

\section{Funding}

This study has not obtained any funding. 


\section{Author contribution (according to the ICMJE recommendations)}

Both authors have contributed substantially to this paper, including:

1. Significant contributions to the conception of the work; analysis and interpretation of data for the work; AND

2. Drafting the work or revising it critically for important intellectual content; AND

3. Final approval of the version to be published; AND

4. Agreement to be accountable for all aspects of the work in ensuring that questions related to the accuracy or integrity of any part of the work are appropriately investigated and resolved.

\section{Acknowledgements}

Not applicable

\section{References}

1. Devlin NJ, Brooks R. EQ-5D and the EuroQol Group: Past, Present and Future. Appl Health Econ Health Policy. 2017;15(2):127-37.

2. Gudex C. The descriptive system of the EuroQol Instrument. In: Kind P, Brooks R, Rabin R, editors. EQ5D concepts and methods: A developmental history. Dordrecht: Springer Netherlands; 2005. p. 19-27.

3. Prieto L, Sacristán JA. Problems and solutions in calculating quality-adjusted life years (QALYs). Health Qual Life Outcomes. 2003;1:80-.

4. Sørensen J, Davidsen M, Gudex C, Pedersen KM, Brønnum-Hansen H. Danish EQ-5D population norms. Scand J Public Health. 2009;37(5):467-74.

5. Council] MDM. Udkast til metodevejledning for vurdering af nye lægemidler [Draft for methodological guide for assessment of new medicines]. 2020.

6. Herdman M, Gudex C, Lloyd A, Janssen M, Kind P, Parkin D, et al. Development and preliminary testing of the new five-level version of EQ-5D (EQ-5D-5L). Qual Life Res. 2011;20(10):1727-36.

7. Janssen MF, Pickard AS, Golicki D, Gudex C, Niewada M, Scalone L, et al. Measurement properties of the EQ-5D-5L compared to the EQ-5D-3L across eight patient groups: a multi-country study. Quality of life research : an international journal of quality of life aspects of treatment, care and rehabilitation. 2013;22(7):1717-27.

8. Grice H. Studies in the Way of Words: Harvard University Press; 1989.

9. Huang Y. Neo-Gricean Pragmatics. In: Huang Y, editor. The Oxford Handbook of Pragmatics: Oxford University Press; 2017.

10. Levinson S. Pragmatics. Cambridge: Cambridge University Press; " 1983. 
11. Horn L. On the Semantic Properties of Logical Operators in English. Los Angeles: UCLA; 1972.

12. Horn L. The border wars. In: von Heusinger K, Turner K, editors. Where Semantics Meets Pragmatics. Oxford: Elsevier; 2006.

13. Horn L. Implicature. In: Horn L, Ward G, editors. The Handbook of Pragmatics. Oxford: Blackwell; 2004. p. 3-28.

14. Levinson S. Presumptive Meanings: The Theory of Generalized Conversational Implicature: Cambridge, Mass.: MIT Press; 2000.

15. Hansen MB, Petersen EN, Poulsen A, Salès-Wuillemin E. When Belief Ascriptions Are About More Than What Is on Someone Else's Mind. Discourse Processes. 2017;54(8):655-69.

16. Clark HH, Schober MF. Asking questions and influenzing answers. In: Tanur JM, editor. Questions about Questions. New York: Russel Sage; 1992. p. 15-48.

17. Schwarz N. Cognition and Communication: Judgmental Biases, Research Methods, and the Logic of Conversation: Psychology Press; 1996.

18. Schwarz N. What Respondents Learn from Questionnaires: The Survey Interview and the Logic of Conversation. International Statistical Review. 1995;63:153.

19. Schwarz N, Hippler H. Response alternatives: the impact of their choice and ordering. In: Biemer P, Groves R, Mathiowetz N, Sudman S, editors. Measurement error in surveys: Chichester: Wiley; 1991.

20. Kennedy S. Projecting the Adjective: The Syntax and Semantics of Gradability and Comparison (1st ed.): Routledge. ; 1999.

21. Aloni M. "Disjunction" In: Zalta EN, editor. The Stanford Encyclopedia of Philosophy. (Winter 2016 Edition) ed2016.

22. Dal Negro RW, Povero M. Cultural and linguistic validation of the NHQ-2 Questionnaire: a specific instrument for assessing patient's usability of inhalation devices. Multidisciplinary respiratory medicine. 2016;11(1):32.

23. Mokkink LB, Terwee CB, Patrick DL, Alonso J, Stratford PW, Knol DL, et al. The COSMIN study reached international consensus on taxonomy, terminology, and definitions of measurement properties for health-related patient-reported outcomes. J Clin Epidemiol. 2010;63(7):737-45.

24. de Vet HCW, Terwee CB, Mokkink LB, Knol DL. Measurement in Medicine: A Practical Guide. Cambridge: Cambridge University Press; 2011.

25. Vésteinsdóttir V, Joinson A, Reips UD, Danielsdottir HB, Thorarinsdottir EA, Thorsdottir F. Questions on honest responding. Behavior research methods. 2019;51(2):811-25.

26. Brenner PS, DeLamater J. Lies, Damned Lies, and Survey Self-Reports? Identity as a Cause of Measurement Bias. Social psychology quarterly. 2016;79(4):333-54.

27. Bergen N, Labonté R. "Everything Is Perfect, and We Have No Problems": Detecting and Limiting Social Desirability Bias in Qualitative Research. Qualitative health research. 2020;30(5):783-92.

28. Rabin R, Gudex C, Selai C, Herdman M. From translation to version management: a history and review of methods for the cultural adaptation of the EuroQol five-dimensional questionnaire. Value in 
health : the journal of the International Society for Pharmacoeconomics and Outcomes Research. 2014;17(1):70-6.

29. Herdman M, Fox-Rushby J, Badia X. A model of equivalence in the cultural adaptation of HRQoL instruments: the universalist approach. Qual Life Res. 1998;7(4):323-35.

30. Noveck I. Experimental Pragmatics: The Making of a Cognitive Science. Cambridge: Cambridge University Press; 2018. iii-iii p.

31. Geurts B, van tiel B. Embedded scalars. Semantics and Pragmatics. 2013;6.

32. Wilson T, LaFleur S, Anderson D. The validity and consequences of verbal reports about attitudes. In: Schwartz N, Sudman S, editors. Answering Questions: Methodology for Determining the Cognitive and Communicative Processes in Survey Research. San Fransisco: Jossey-Bass/Wiley; 1996. p. 91114. 